\title{
Leadership 2.0 in Action: a Journey from Knowledge Management to "Knowledging"
}

\author{
Bonnie Cheuk* \\ Ex-Global Head of Knowledge \& Information, ERM \\ Citi, Global Transaction Services \\ Global Director of Knowledge \& Collaboration \\ Citigroup Centre, 13th Floor, CGC1, 33 Canada Square, London E14 \\ 5LB, United Kingdom \\ E-mail: bonnie.cheuk@gmail.com
}

\section{Brenda Dervin}

Professor \& Joan N. Huber Fellow in Social and Behavioral Sciences School of Communication

The Ohio State University, Columbus, Ohio USA

E-mail: dervin.1@osu.edu

*Corresponding author

\begin{abstract}
Leadership 2.0 is a set of alternative management values and practices driven by a set of coherent assumptions about the nature of human communication. In this paper, the authors argue that Leadership 2.0 is critical to make Web2.0 work. This paper is informed by Dervin's Sense-Making Methodology (SMM) as an approach to design knowledge sharing platform incorporating Web2.0 features which allow user-generated content and have a stronger emphasis on collaboration and interaction amongst users. SMM is a philosophically derived approach which allows knowledge management (KM) researchers and practitioners to more fully understand and listen to user's needs so as to inform the design of dialogic KM practices and systems to promote knowledge sharing. This paper presents a "Safety Moment" project to illustrate how SMM has been applied to inform the design of a Web2.0 enabled 'knowledging' application in Environmental Resources Management (ERM), the world's largest all-environmental consulting firm. The project discussed has been implemented since January 2008 as part of ERM's commitment to improve Health \& Safety Performance to ensure all ERM employees, contractors and clients are safe at work. The use of SMM informed Web2.0 application has correlated with increased staff satisfaction, increased company reputation and reduced risks.
\end{abstract}

Keywords: Leadership 2.0; Web2.0; Knowledge Management; Knowledging

Biographical notes: Dr Bonnie Cheuk has a passion in promoting knowledge sharing, smart working, two-way communication practices and innovation in order to deliver ambitious growth targets at multi national companies. Bonnie is currently the Global Director of Knowledge \& Collaboration at Citi, Global Transaction services. Emphasizing the importance of Leadership 2.0, she has been one of the pioneers in introducing Web 2.0 tools in the business setting which lead to tangible business outcomes. Her track records include helping Environmental Resources Management (ERM) won the Environmental 
Business Journal Award for Organizational Innovation (2008) and the Neilson's Top 10 Best Intranet Award 2009. Whilst she was the Director of Knowledge Management at the British Council, two of her projects were shortlisted as finalists for the Information Management Award (IM2004, IM2005). From 1999 to 2002, she worked for Arthur Andersen business consulting and has helped its clients implemented knowledge strategy in both the Asia Pacific region and in the United States. Originally from Hong Kong, Bonnie received her Ph.D. degree in library and information science in 1999. Since then, she has been applying Dervin's Sense-Making Methodology and Snowden's thinking to design and implement knowledge management practices. Bonnie can be contacted at bonnie.cheuk@gmail.com Follow her on http://bonniecheuk.blogspot.com and www.twitter.com/bonniecheuk .

Dr. Brenda Dervin is Full Professor of Communication and Joan N. Huber Fellow in Social and Behavioral Sciences at Ohio State University where she teaches courses focusing on in-depth interviewing, qualitative and focus group research, methodological philosophy, and audience/user analysis. She has worked on the development of Sense-Making Methodology since 1972 and she and colleagues have applied it to numerous fields, including as examples human computer interaction, knowledge management, citizen participation, health communication, telecommunication policy, arts audiences, web design, and information seeking and use. Dervin is fellow and past president of the International Communication Association. She earned her doctorate in communicate from Michigan State University, and holds as well an honorary doctorate in social sciences from the University of Helsinki. Prior to entering academia Dervin worked as a public information specialist for a variety of nonprofit organizations and graduated with an baccaleureate emphasis in communication from Cornell University.

\section{Introduction: Leadership 2.0, Web2.0, Intranet 2.0 and Enterprise 2.0}

Knowledge Management (KM) in the enterprise setting has increasingly been associated with the use of collaboration technologies, social computing and interactive online communities to leverage collective insights of all staff to inform decision making and promote innovation. Many KM practitioners argue that finally the right technologies are available at an affordable cost to make knowledge sharing happen.

McAfee (2006) introduced the term Enterprise 2.0 as shorthand for the use of Web2.0 by businesses and especially on organizations' intranets and extranets in pursuit of their goals. In ERM -- Web2.0 has been introduced using what ERM labels as LANES principles (Cheuk, 2007):

- Lateral Communication, i.e. supports top-down, bottom-up and lateral communications.

- All staff can participate if they want to, i.e. no specialized IT skills are required.

- Networking, i.e. building of business and social networking across teams and geographies.

- Expertise visualization, i.e. visualize the expertise that staff do not know exist. 
- Selfishness yet helping others, i.e. focusing on satisfying the 'selfish' immediate needs of a user and the by-product by highlighting the collective intelligence which creates more value to all staff.

Despite high enthusiasm and great expectations, the literature is replete with examples of failures in virtually every organizational context (Stephens, 2009), In the KM context, typical unsuccessful case tends to be about a blog or forum is set up to invite all staff to engage in a dialogue, it turns out that few people participate because: (a) staff members didn't trust their voice will be genuinely heard; (b) some junior members did not feel comfortable sharing their ideas with experts or senior staff.

Few Web2.0 tools have been consciously designed to demonstrate that experts are actively listening and actively taking input seriously. Nor have design tools been applied to develop systematically constructive ways of encouraging input by those who have felt unheard and disempowered. Yet, organizational research (e.g. Putman \& Kline, 2006; Weick \& Browning, 1986; Weick \& Sutcliffe, 2001) has repeatedly shown that it is sometimes these very voices that have the clearest visions of what may be going organizationally. Bottom line, too often Web2.0 and other online dialogue applications are still designed with top-down communication implicitly assumed as outcome. From a communication perspective, this fails because genuine dialogic communication requires a two-way quid pro quo.

In the context of repeated online communication failures, what are the missing pieces to make Web2.0 work in the workplace? We argue here that the missing pieces involve a reconceptualization of what $\mathrm{KM}$ is about as well as the design of $\mathrm{KM}$ procedures. As a KM practitioner, the senior author of this paper has gained the following insights when introducing Web 2.0 in the workplace:

1. To make Web2.0 works, we need Leadership 2.0. However, while many uses of the term Leadership 2.0 are evident in practical and research oriented literatures, our use here goes far beyond the usual emphasis on knowledge sharing as if this is somehow a magical outcome of facilitating more message sharing.

2. Thus, Leadership 2.0, as discussed in this paper, requires a different way of thinking about 'knowledge management' and 'knowledge transfer'. It requires leaders, managers and employees redefine knowledge transfer not as a thing called 'information' to be transferred from one bucket to another, but as a process of meaningful and evolving knowledge exchange. In this paper, this process is referred to as 'knowledging' and the 'information' involved is referred to as 'knowledgings' as participants make and unmake their understandings as they move through changing and often elusive situations, as they reflect on their own understandings, as they hear and apply the understandings of others, as they struggle together to bridge knowledging gaps. When emphasis moves from 'knowledge' to 'knowledging', genuine dialogue and communication can begin to take place. As a result, both senders and recipients are facilitated in gaining new insights, and learning and/or unlearning as circumstances demand. The lines between senders and recipients become blurred. They become coparticipants. In short, the transmission model of knowledge management does not apply even when seemingly made more participatory by an emphasis on creating more message exchange. Increasing the volume of 
messages exchange in the absence of the use of meaningful communicating procedures ends up being noise-sharing rather than knowledging-sharing.

3. Leadership 2.0, as we think about it, also redefines information literacy in the workplace. It takes information literacy to a strategic level (Cheuk, 2008). Leadership 2.0 trusts that employees will find and use information to help them get on with their work at the time they need to. Staff do not need to be spoon fed with information, and research shows spoon-feeding rarely is effective, The focus of information literacy in the workplace places less emphasis on Web2.0 tools training but more on guidance to adopt good two-way communication procedures, such as listening, evaluating, presenting and visualizing ideas with the audience's needs in mind.

4. Leadership 2.0, again as we use the term, redefines what learning in the workplace means. Learning goes beyond formal training, structured staff appraisal and staff development programs. Employees learn through selfreflection of good practices and mistakes, as well as listening to how other employees (both experts and novices) look at issues in same or different ways. Mistakes are tolerated. Hunches are invited. Through the learning process, the experts, the novices, the senior executives and the front line staff learn and unlearn. All learners are empowered to become more selfreflective, and experts and authorities lower their egos to listen and to learn from others.

Many KM practitioners have commented that Leadership 2.0 of the kind described above is not easily found in corporations. Since the early 20th century, most industrialized countries have implemented a set of management disciplines that have focused almost exclusively on top-down command-and-control strategies (Putnam \& Krone, 2006). Although it remains a much contested issue in organizational communication research, command-and-control procedures have been shown to have decided limits even in these presumably routinized contexts and even more so in complex organizations whose core purposes involve knowledge sharing and meeting the demands of changing, sometimes chaotic environments. For our purposes here, Leadership 2.0 refers to a set of alternative management values and practices designed to allow organizations and their workers to move from command-and-control structures to genuinely collaborative ways of working.

While many have called the move to Leadership 2.0 a "cultural change", in this paper we focus on it as a change in the very way we think about communication. The purpose of Leadership 2.0, as we define it, is to promote "knowledging" -- in essence the using of systematic communication practices that enable participants to make and unmake, refine and expand, exemplify and abstract their "knowledging" by using systematically designed processes of self-reflection and shared communicating.

\section{Literature Review: KM philosophies}

It is useful to review the literature of knowledge management and its development overtime to understand the changing philosophical assumptions which guide the development of KM practices/systems including Web2.0 tools.

Many definitions of knowledge exist. The definitional differences arise from competing, ontological and epistemological assumptions. A review of these differences is 
beyond purposes here. In the context of knowledge management, a number of useful overviews and critiques exist (e.g. Brown \& Duguid, 2000; Dervin, 1998, 1999; Hildreth and Kimble, 2002; Nonaka and Peltokorpi, 2006; Snowden \& Stanbridge, 2004; Souto, Dervin \& Savolainen, 2008; Wenger, 1998; Wilson, 2002).

Informed by these reviews, we concluded that first generation KM practices/systems have been informed primarily by the positivist philosophical assumption that "knowledge" is an object which is external to human beings and can be managed by making 'tacit' knowledge explicit by investing in KM systems which 'capture' the knowledge of experts in databases, manuals, books and reports, and then sharing it in a hard form. It is assumed that increasing the available quantity of 'codified' knowledge will have a positive linear impact on operational costs and avoid reinventing the wheel. A fundamental difficulty with this view, of course, is that as social scientists have well documented, there are numerous processes that intervene between external evidences of codified knowledge and internal knowings. This is why some argue (e.g. Wilson, 2002) that knowledge cannot be managed. The KM mandate is further muddied by the realities of our increasingly complex organizational climates and the often incomplete and elusive character of that "stuff" we humans call "data" or "information" or "knowledge".

Informed by these arguments, there are scholars and practitioners who recognize the limits of the positivist philosophical assumptions and propose alternative views that differ from those applies to first generation KM systems and practices. The various authors proposing these alternatives converge on essentially four conceptualizations all of which mandate in one way or another a more communicative or dialogue-based view of $\mathrm{KM}$ specifically in applications labeled as KM but also in other organizational contexts where "knowledge management" is a primary focus. See for example (Brown \& Duguid, 2000; Browning \& Boudes, 2005; Dervin, 1998, 1999; Fairhurst \& Putnam, 2004; Hildreth and Kimble, 2002; Nonaka and Peltokorpi, 2006; Snowden \& Stanbridge, 2004; Souto, Dervin \& Savolainen, 2008; Weick \& Browning, 1986; Weick \& Sutcliffe, 2001; Wenger, 1998):

1. Focussing on the need to allow communicative interrogation and interpretation of knowledge as seen from recipients' perspectives.

2. Cultivating knowledge workers by facilitating their learning through selfdescriptive awareness.

3. Redefining knowledge as not just about 'facts' but also direction, ideas, support, confirmation and connection with other people etc. Knowledge can also sometimes be 'objective' and sometimes be 'subjective' and 'emotional'. Sometimes, as well, knowledge can be confusions and muddles which when shared clarify what's going amiss.

4. Recognizing that knowledge -- is embedded in a social context and is at least in part defined by power and in part defined by status. Knowledge sharing can be more or less effective depending how power is acknowledged.

This understanding of knowledge - through the eyes of the knowledge user provides an alternative perspective and foundation to design KM practices/systems that:

1. Look beyond information itself and promote knowledge sharing in the context in which people work . 
2. Put more emphasis on narratives and story-telling which share knowledge that is rich in context.

Web2.0 technologies seem to allow ready implementation of these assumptions and when they become available in the enterprise setting. There are however issues which need to be addressed:

1. It seems very easy for a community of practice to be set up to allow members to exchange ideas. However, the result can be the reinforcing of silos that resemble current organizational structures and hierarchies rather than promoting cross-silo conversation.

2. It becomes very easy for a sub-group of like-minded colleagues to dominant the communicating space in online discussions by, for example, commenting on each other's blogs or being the ones to dominant conversations in a wiki. While the quantity of user-generated content may have increased, the cross-fertilization of ideas does not necessarily improve.

3. While it becomes very easy to publish more content, this does not mean that the knowledge offered will necessarily be attended to or utilized to inform decision making. Research in communication clearly shows that an increase in talk that leads to no acknowledgment, action or improved decision-making can disappoint employees and lead to job alienation.

4. It becomes very easy to assume that power differentials do not exist in online environments when in fact they do so as much as in face-to-face meetings. An inclination to increase user adoption of Web2.0 tools needs to be balanced by providing safe, constructive and sometimes anonymous spaces for exchanging ideas (online or offline).

The difficulty we have when focusing on these new technologies that are so conducive to people speaking at each other is that they are based on a communication logic that Dervin (2010) suggests proceeds without genuine communication and exchange. In her extensive reviews, Dervin has documented how communication logics have moved from an emphasis on top-down transmission to efforts to pigeonhole people into demographic, personality, and cultural boxes in order to make transmission more effective. These approaches have not worked well and less so as our organizational climates become more complex. Now, impelled by the strengths of new technologies, we have the dominant emphasis on letting communication spontaneously flow between participants Dervin argues, however, that this logic is merely the opposite side of the same coin. Top-down transmission attempts to control messages so only the right ones flow. Uncontrolled lateral transmission too often merely increased the number of messages flowing. This, Dervin charges, merely introduces a communication logic that easily becomes a "Tower of Babel". What is needed is a logic that enables participants to come to understand each other's meanings and the grounds (experiential, cognitive, emotional, and even sometimes physical and spiritual) that human beings move from when knowledging. Dervin says this new kind of communication logic requires that we systematically apply into KM designs the kinds of communication actions that people require if they are to understand each other across organizational silos and forge effective collaborations informed by each others knowledgings.

Thus, we argue here that the design of Web2.0 applications must promote 'knowledging' rather than knowledge transmission. It requires attention to the disciplining of communication procedures in order for organizations, and the human beings who work in them, to reap benefits (Dervin, 2008). The most disciplined and 
methodological approach to promote 'knowledging' which is the result of genuine twoway dialogue (conducted offline and/or online) is found in the discourse community focussing on communication led by Dervin. The next section will present Sense-Making Methodology in detail.

\section{An Overview of Sense-Making Methodology}

Dervin began to develop Sense-Making Methodology (SMM) in the late 1960s as an alternative approach to understanding human communication. As a line of work, it fits within a communication tradition that assumes that communication must be studied communicatively -- a on-going practices in which people make and unmake sense of their changing and sometimes elusive worlds through internal and external communicatings.

The approach has always been associated with a set of metatheorectical assumptions that methodologically inform specific methods. One useful example for illustrating this point is the SMM Micro-Moment Time-Line interviewing approach (Dervin, 1983, 2008). The approach was widely adopted by Library and Information Science researchers to study information seeking and using behaviour in the 1980s and became main stream in 1990s in a variety of research contexts, e.g. the study of communication campaign and media audiences; the study of information seeking and use; the study of patients as recipients of health messages. SMM's applicability to design knowledge management practice was introduced by Dervin in 1998 when she called for alternative KM practices (Dervin, 1998). Dervin suggested that KM practitioners (as well as many other categories of system practitioners) continued to struggle with issues which she and colleagues have been zeroing in on since 1972 (Dervin and ForemanWernet, 2003). Those issues result from our organizations continuing to use transmission communication logics that are simply not communicative.

Dervin's Sense-Making Methodology is defined as a set of meta-theoretic assumptions, a foundation for methodological guidance, specific research methods (both for data collection and for question framing and analysis), and a set of communication and design practices. All of these elements are generated from a philosophical perspective that regards information or knowledge as a human tool designed for making and unmaking sense of a reality that is simultaneously both chaotic and orderly (Dervin, 1992; Dervin, 2008).

Sense-Making makes no distinction between data, information, knowledge and wisdom. Knowledge is the sense made at a particular point in time-space by an individual. As Dervin says, sometimes it is shared and codified; sometimes a number of people agree upon it; sometimes it is entered into a formalized discourse and gets published; sometimes it gets tested in other times and spaces and takes on the status of facts; sometimes it is fleeting and unexpressed; sometimes it is hidden and suppressed; sometimes it gets imprimatured and becomes unjust law; sometimes it takes on the status of dogma; sometimes it is besieged and surrounded by confusions and angst.

In this paper, the authors use the label 'knowledging' to refer to the gaining of new knowledge through the users' eyes in order to serve users' needs. This is informed by Dervin's $(1998,2003)$ call for understanding knowledge management as communication; and communication as communicatings, as verbings. Thus, knowledge management becomes the designing of 'sense-making' and 'sense-unmaking' (or 'knowledging') practices and systems to allow users to self-reflect as well as to gain multiple perspectives from listening to what others can offer, taking into account the 
power issues which can constraint what users are able to ask for, and ultimately to address sense-making needs at specific moments in time-space.

In order to design $\mathrm{KM}$ practices and systems to understand 'knowledging' processes, Dervin argues that KM practitioners and researchers have to take into account first and foremost an understanding that most of the things that organizations have tried to use to "predict" communication behavior (e.g. attending to messages, thinking about them, using them) simply have not predicted well. While some variance is accounted for it is usually very modest and further does not help us in communicating well with specific individuals. Thus, the entire roster of things about people that have been assumed to be constant attributes that predict don't work when we think communicatively. This includes age, gender, geography, work role, generation Y, department, function, service area, industry group, client team, task, lifestyle etc. Further, even outsider assessments of situational conditions do not predict well because situations are seen differently by different observers. Not only do these assumed "constancies" not predict well at one time, even more difficult is that people are constantly changing their sense-makings so what might have "predicted" modestly well yesterday will not do so for the same individuals tomorrow.

Thus, Dervin is asking KM researchers and practitioners to focus on studying and helping users-in-situations moving through time-space. For Dervin, this mandate not only informs user studies but informs the design and implementation of systems and practice. Bottom line, Dervin calls for the application of communicative procedures -- procedures that are informed by an understanding of how communication can work well -- to every aspect of research, design, and practice because these activities are all fundamentally driven by communication. The difficulty with merely inviting more message flow, Dervin challenges, is that there are yawnings gaps between what people think about and make sense of internally and what our systems and societal conventions allow them to talk about. Take, for example, the organizational emphasis on best practices which defies the realities that people learn the most from their struggles and failures and those of others. Further, best practices are usually offered as solutions out of context when in actuality they have themselves have arisen out of struggles.

Thus, what happens when we give people access to use the new ITs (such as Web2.0 tools) to access or contribute ideas, information, content or knowledge is that messages flow without opportunities for sense-making -- for knowledging to happen. Dervin argues that most often what happens can be seen as kinds of "spontaneous talking shop" events that do not well serve the communicative design of KM systems and practices. Spontaneous communication, too often, reinforces current habits and cower structures. As a result, the communication flows miss the vital but hidden understandings that users have locked within them and do not readily share.

Evidence to date about what is happening with online communication is that these communication failures become even more exaggerated as spontaneous messages flow in forums, blogs and tweets without genuine listening and dialogue with one another. While clearly these new tools are seen as liberating by many users, evidence shows that mostly people who already agree with each other attend to each other. In short, all this increasing communication activity is not facilitating what we think of as knowledging -where people share and hear across their different perspectives; where they share their understandings of the different pieces of sometimes complex organizational puzzles; where they reflect on their own sense-makings, where they come from and how they have helped and hindered; where they share their muddles and hunches and work together to 
come up with new understandings despite the reality that some understandings will remain incomplete.

Based on these arguments, we propose that the explicit design of communication procedures is critical to facilitate 'knowledging' and cannot be left to chance. This means that in designing Web2.0 tools, one needs to allow learning to be shared in a way that welcomes both majority and minority voices and allows users to connect internally within themselves across time-space as well as with each other. Ultimately, Web2.0 enabled KM practices/systems should allow users to be able to move forward on what they need to make sense of at the time they need to do so. Web2.0 tools are generally seen as 'easy to use' and users can be self-organized without the need to moderate and facilitate the dialogue. We propose that KM practitioners need to think otherwise.

Sense-Making Methodology is not about persuasion or dictating the outcomes on behalf of users (e.g. deciding what users choose to do and think as a result of having access to knowledge residing in KM systems). Companies designing Web2.0 enabled KM systems with the sole purpose of indoctrinating employees to adopt best practice policies, methodologies (as defined by experts) or to conform to senior managers' wish will not find SMM useful. Dervin, in fact, assumes that KM systems that make these assumptions may, under some circumstances, get obedience without understanding and, thus, impede long-term organizational growth. SMM focuses on communication processes rather than outcomes. Accepting that SMM might be seen as utopian in its vision, Dervin believes that by introducing disciplined and dialogic communication practices, the methodology helps surface multiple perspectives, and open up dialogue and possibilities. Further, while applying SMM may increase uncertainty in some ways, it allows users to 'learn from within' and reflect deeply to understand and address their own needs as well as the needs of others and their organizations.

In introducing Sense-Making Methodology, Dervin has stated clearly that "the bottom-line goal of SMM from its inception has been to find out what users - audiences, customers, patients, clients, patrons, employees - 'really' think, feel, want, dream" (Dervin, 1998, pp.39). Dervin always places the term "really" in quotes because she assumes that the best we can do is surround that which we cannot touch and cannot freeze or bend to our wills.

She has elaborated that "Sense-Making uses a central metaphor - the metaphor of human beings traveling through time-space, coming out of situations with history and partial instructions, arriving at new situations, facing gaps, building bridges across those gaps, evaluating outcomes and moving on. This does not imply that all sense-making is purposive. Rather, it suggests that gap-bridging is mandated by the human condition. SMM's central meta-theoretic concepts include: time, space, horizon, movement, gap and power. Its central operational concepts include: situation, history, gap, barrier, constraint, force, bridge, sense-making strategies, outcomes, helps and hurts. These concepts are illustrated in Diagram 1, what Dervin calls the "Sense-Making Methodology Metaphor".

"This metaphor provides guidance for thinking about people, talking to them, asking questions of them and designing systems to serve them. In capsule it says, look to the gap: this is where you will find the action in sense-making and sense-unmaking; in communicating; and, in the creating, seeking, using and rejecting of information and knowledge". Earlier versions of the metaphor exists (e.g. Dervin \& Foreman-Wernet, 2003), this 2008 version introduced a recent refinement showing a person carrying an umbrella moving across time-space to better reflect how SMM defines context. It also shows gaps all over the picture to reflect the meta-theoretical assumption that 'gappiness' is a fundamental human experience which is at the core of SMM. (Dervin, 2008). 


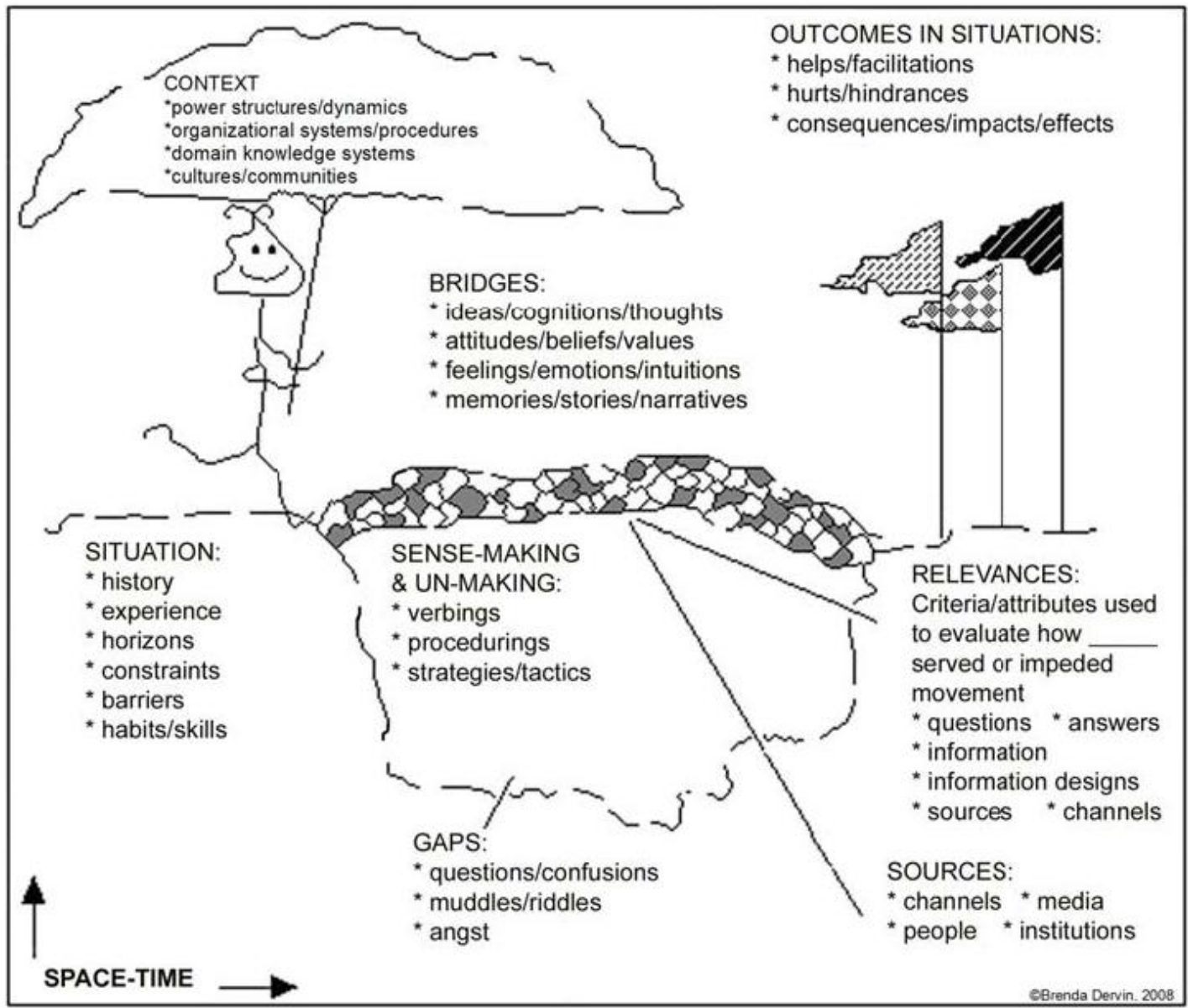

Diagram 1: Dervin's Sense-Making Metaphor (Dervin, 2008)

The SMM metaphor asks researchers to understand users' needs by looking at the SMM triangle of 'situation', 'gaps' and 'help', and by asking these questions: (Dervin, 1992):

- What led you to this situation?

- Where did you want to get to?

- What gaps did you see?

- What got in the way?

- What help did you get along the way?

- What emotions/feelings did you experience?

- If you had a magic wand, what would you like to happen?

SMM applies this metaphor in different ways depending on research and practice purposes and to different ranges of time-space. For example, in some applications attentions are focused on entire situations; in others, on micro-moments of time-space within situations. Further, the depth of attentions to either situations or specific micro- 
moments in situations vary from purposively more shallow to purposively very intensive and deep. This choice depends on purposes and the extent to which stereotyped understandings dominate the social context shielding from view how individuals struggle to make sense of their relationships with themselves, with others, and with their organizational/social contexts.

In implementing methodologically this continual struggle of humans to navigate between their inner and outer worlds, their own senses of self and the demands of organizations and communities, Dervin is emphasizing that we must address issues relating to how power (internal and external) both can enable and/or constrain human sense-making and human knowledge sharing. Therefore, in designing Web2.0 enabled KM practices and systems, she stresses that:

1. We must provide safe spaces for people to attend to power issues so that they are willing to tell us things that ordinary interviewing practices miss entirely. If this cannot be done in public arenas, then anonymity structures need to be added.

2. We need to be cautious of one-way knowledge transfer from experts to novices. We must be aware of power issues and consciously promote disciplined communications procedures to invite two-way sharing and negotiating of meanings (Dervin, 1989).

3. We must be careful not to design KM systems/processes from the experts' perspectives. Instead, we must look for differences in how people see their worlds (e.g. information that is presented to them), and also the differences in how they 'make their worlds' (i.e. construct a sense of their worlds in their subject domains and how things works). Years of SMM research has shown that if we conceptualize the human condition as a struggle through an incomplete reality, then the similar struggles of others become more informative to individual and collective sense-making, and, thus, to knowledging.

\section{Designing online 'Safety Zone' at ERM: Informed by Sense-Making Methodology}

Environmental Resources Management (ERM) is the world's largest all-environmental consultancy firm which provides environmental, health and safety, risk, and social consulting services. ERM delivers innovative solutions for business and government clients, helping them understand and manage their impacts on the environment around them. ERM has 137 offices in 39 countries and employs over 3,300 staff. More information is available on www.erm.com.

One of ERM's core services is to help industrial clients around the world achieve their environmental, health and safety compliance obligations, reduce accident and injury rates, and minimize impacts on the environment. While many companies have Safety Programs in place, they can become dry, corporate and unimaginative over time. While compliance-driven Safety processes are a critical part of any Safety program, they can be seen as top-down, bureaucratic and lack imagination. Many EHS directors ask: How can we add a human touch to the Safety program? How can I better engage and communicate with employees to change people's behaviors and understand the importance of Safety at work? Can Web2.0 open up new possibilities? 
ERM cares about its own Health \& Safety Performance and is committed to ensuring ERM is a safe place to work for employees, contractors and clients. ERM faces the same challenge that its clients do and has asked the same questions. In 2008, ERM began to implement its next generation Safety program and has fully embraced its award winning intranet named 'Minerva' and utilized Web2.0 to share knowledge on Safety related issues and policies as a strand of work to improve ERM's safety culture (Cheuk, 2009). This section draws on ERM's own experience adopting Web2.0 features on Minerva and discusses how Dervin's Sense-Making Methodology has contributed to the art of designing Web2.0 enabled 'Safety Zone' to promote the 'knowledging' of Safety topics.

\subsection{Level 1: The Web2.0 Beginning - Putting in place a Blog}

Prior to the introduction of Minerva, employee communications about the Safety program had only been one-way. Regular headline News items would appear in the company newsletter to inform staff of Safety policies and procedures. The Safety intranet site was centrally managed by the Environmental Health \& Safety (EHS) Director where all safety policies and documentations were stored. Although face-to-face meetings and training were organized in selected offices, the director was not able to easily engage with all employees worldwide. The knowledge management model then was a transmission model where best practices were defined and transferred from the EHS director (and his team of experts) to all employees with a focus on compliance.

In January 2008, ERM began its journey to fully leverage the power of a Web2.0 enabled 'Minerva' intranet to explore new ways of involving all staff in Safety dialogue and to co-create the next generation safety culture together.

The first initiative was to bring our face-to-face Safety ritual online. In ERM, all face-to-face meetings start with a Safety Moment when a member of staff will stand up and share a recent safety issue and the learning points. This ritual has been taken online by establishing a 'Safety Zone' on the Minerva homepage, which is automatically launched whenever employees log on to their computers. The 'Safety Zone' provides a virtual common room for all ERM employees to experience the weekly safety moment together.

The Safety Zone is designed using a blog feature. On clicking on the Safety Zone as shown in Diagram 2, users can access the weekly blog posts - some posts embed video or podcasts - that every staff can comment on to share their experiences on a safety topic and how to prevent similar accidents from reoccurring. Each week, a colleague from a different part of the world will contribute a Safety Moment. The blog talks about real life safety incidents ranging from near miss situations at natural gas facilities and how good communication can help avoid accidents from driving in bad weather and checking for insects that bite before embarking on certain tasks. The discussions entail lessons learnt and how such situations can be avoided.

\subsection{Level 2: Not a 'spontaneous' blog}

ERM has taken a more disciplined approach to structure the dialogue which happens on the 'Safety Zone' blog. Unlike a free form blog where staff can post any questions and answers around any Safety issues, some communication procedures are put in place in facilitating more in-depth conversation. SMM alerted us that spontaneous dialogue can reinforce old stereotypes and patterns and existing power structures. To attend to this 
issue, when the safety Zone was first rolled out, a communication procedure was put in place to guide the sharing of any Safety Moments. Whether the participants were ERM employees or the EHS Director, they had to follow a structured template to invite the sharing of deeper thoughts:

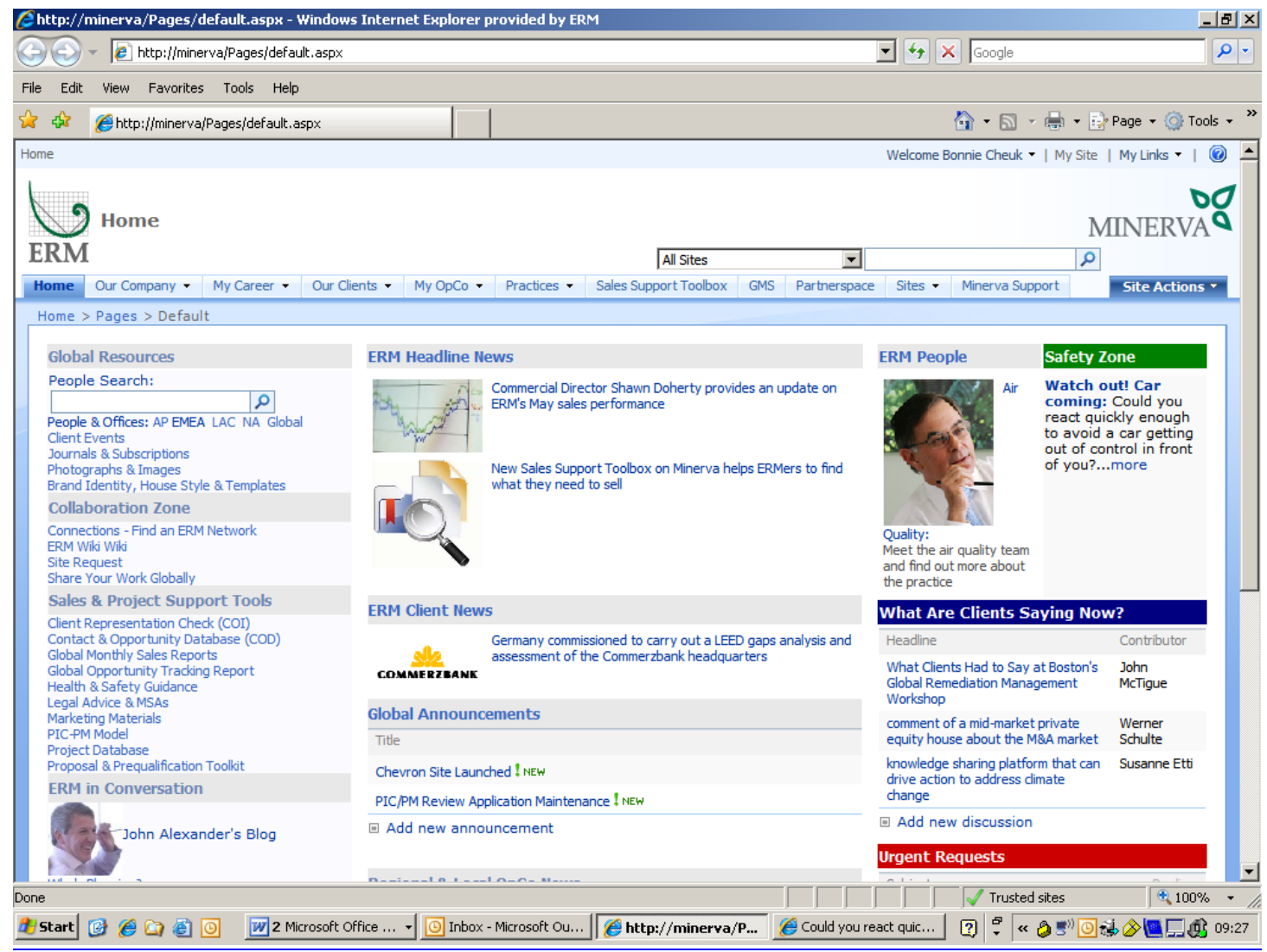

\section{Diagram 2: Minerva homepage showing Safety Zone}

- Describe a situation when you faced a Safety issue at work (e.g. 'An ERM subcontractor was drilling soil borings when they struck an underground electrical line. The electric company had removed at least on electric line but was no longer aware of the remaining line. Although no injuries were sustained, one service line was completely severed, with a second line partially severed').

- What confusion / questions / muddle did you have at that time? (e.g. 'I wonder what policies I should follow? What should I have done to prevent this from happening?').

- What helped? What hurt? (e.g. 'I remember the slogan 'I see it, I own it', I know I need to do something to avoid my staff and contractors from getting into this situation'). 
- $\quad$ Did you see that there are forces which you cannot control? (e.g. 'I felt that as the subcontractor was not an ERM employee, should I raise this issue with them').

- If you had a magic wand, what could have helped to prevent this from happening? (e.g. 'I would ensure that we insist our subcontractors also have to carry out all the required checks before we start any drilling work').

- At the end of the blog post, the contributor has to post this question to all staff 'Does anyone have a similar Safety situation that you would like to mention for our benefit?'.

We are aware of power issues and that some staff may not be willing to voice their opinion or associate their names with a safety issue. The EHS Director welcomes colleagues who are hesitant about sharing their voice on the blog to send their thoughts by email to him. He will then anonymize the contribution and post it on behalf of the colleague. For example, a local Safety leader was not sure if he should be sharing a Safety Moment because he thought it could be a very local issue. He hesitated at first, the advice he was given was that the EHS Director welcomed all Safety Moments, and if he did not want to submit the local issue under his own name, he could send it to the EHS Director to be posted up on his behalf. Another participant was concerned that his comment on a Safety policy would offend a senior colleague, so his comment was sent to EHS Director and posted up as an anonymous comment.

\subsection{Level 3: Beyond knowledge transfer - Learning from oneself and from others}

The thinking behind asking employees to write a Safety Moment down on a blog (or an email sent to EHS Director) or to share a similar situation one has experienced, is that self-reflection is a learning and 'knowledging' exercise. Self-reflection (i.e. transferring knowledge from self to self) does not traditionally fall into the KM agenda as source and senders are usually seen as two different parties. Allowing other staff to reflect on experience shared by others, and then relating others' experience with self is another way of gaining deep insight or learning. Inviting all staff to share similar situations at the end of each Safety Moment aims to achieve this goal.

This new way of thinking about 'knowledging' as learning from oneself, and learning from others through self-reflection has not been explicit in KM practices when the focus is on corporate information management, information architecture or taxonomy management, with the aim to transfer information from the source to the recipients. Although KM and learning should be closely linked, in practice, corporate KM function tends to align closely with IT or strategic planning or communication (defined as marketing and advertising) department. The alignment between KM and organizational development and learning functions is rare.

Informed by SMM, in this ERM example 'knowledging' and learning becomes inseparable, as we move away from managing knowledge as 'thing' (e.g. Safety document repository, Safety news alerts) to focus on the 'flow' of knowledgings -- (i.e. the moments when people make sense of Safety Moments that others have experienced, allowing them time to reflect and do some self sense making). In this approach, knowledge management is redefined as 'knowledging' and communicating and learning become central and integrated part of knowledging processes. 


\subsection{Level 4: From top-down communication to promoting genuine two-way Safety Dialogue}

From the onset it is made clear that the ground rule is to allow employees to listen and learn from one another, rather than debating and arguing whose best practices are the best. All staff are asked to share their comments in a non-accusatory style. It is made clear that the Safety Zone is a space for all staff to talk about Safety issues with the Safety leader leads by example. It is expected that all staff treat one another with respect, and are not there to attack and promote one's ego.

The coaching sessions with the EHS Director were important. At one point, he raised concern with regard to a colleague posting an 'inappropriate' suggestion on the blog and was asking the intranet team to help delete the comment. The EHS Director eventually learned that he has to let go of his own expert status and ego, and step back and listen to what other employees have to say. Instead of going in and offering the best practice expert's advice, he has learned to clarify misunderstanding, point to useful documents which help users to address a Safety issue. Instead of being the know-it-all, he becomes the facilitator. The post was not taken down. Rather, the Director went in to explain how the situation has been/could be handled in other ways.

In another example, when the EHS Director spotted a trend that there were 9 near misses related to Sub-Surface Clearance (SCC) within 2 months, he organised a global one hour Safety Stand Down to ask colleagues to reflect on what went wrong and how to avoid serious injuries. After he posted the SCC Safety Moment on the blog, a sceptical comment titled 'Thanks for nothing' came in, the contributor challenged EHS Director that ERM carried out many SCC jobs in a year, and there were many which we did very well, why did we only look at the problems but did not celebrate our success. EHS Director then calmed himself down, and posted a comment acknowledging this concern, took the opportunity to explain why it was important to identity trends to avoid major injuries, and admitted that future Safety communication should place additional emphasis on successful examples. This exchange has helped all employees to better understand the importance of Safety as the EHS Director shared his thought process and struggles he faced leading to the Stand Down exercise.

When the blog was first launched, the former EHS Director was so committed and enthusiastic that he replied immediately to any comments posted up, and was seen as dominating the discussion. He was immediately coached to understand his role has changed from the expert to a facilitator to provide space for staff to exchange ideas. He eventually took up a moderator role and he would offer his own insights towards the end of the weekly dialogue.

In another example, an employee has shared a Safety Moment pointing out that the colour of a yellow Safety Jacket can attract insects in the forest during summer time. The feedback, which was a surprise to the Safety team as they had not considered this in the past, was taken seriously and led to a change in Safety guidelines. The suggestion to change the guidelines was made publicly by a senior executive leader as a blog comment. This sends a strong message that the voice of our employees is being heard, valued and utilized to inform decisions. It also sends a clear message that the leaders and experts are learning from ERM employees. And, it is an excellent example of how organizations need the knowledging inputs of their workers because, as SMM fundamentally assumes, no expert can possibly surveill all relevant inputs.

Previously, Safety News Alerts came from the EHS Director (i.e. the expert) whose role it is to inform/educate/download and ultimately ensure compliance. Currently, 
our Behavioural-Based Safety Program becomes a learning experience for all staff to make sense of the importance of Safety, using a combination of Web2.0 tools and blending 'knowledging' procedures that integrate 'communicating' and 'learning' to allow our staff to draw on their own experience and build commitments to Safety from within.

\subsection{Level 5: Rich dialogue provides rich context and gives meaning to faceless safety procedures}

At the end of each Safety Moment, there is a formal reminder that there is a Safety intranet to download safety guidance/procedures and to access to the Safety Management Systems. The stories shared online create the rich context to help staff to be more motivated to use the Safety systems, forms and policies. When an employee suggests a safety procedure should be followed, the document is introduced in the context of a real situation. This gives more personal meaning to the documents as staff have the chance to reflect on their own experience before they are directed to these documents. The interaction and the conversation have given 'life' to the documents and best practices sitting on the Safety Intranet Document Repository.

The blog compliments rather than replaces the traditional intranet which provides Safety information. The Safety intranet site comes with a document repository. In order to provide an update on Swine Flu, for example, a Swine Flu Channel has been set up and uses RSS feeds to ensure that the latest information from official sources get published immediately. A monthly alert summarizing all the Safety highlights is delivered to all employees via our ERM's internal monthly newsletter.

In addition, the newly launched safety intranet comes with multimedia channels to deliver regular podcasts and video casts. For a two month period, the intranet hosted an interactive forum which supported a global consultation exercise discussing how ERM should implement our next generation Safety management and reporting system. The forum supplemented face-to-face consultation meetings and gave voice to any employee who has not had the chance to participate in face-to-face meetings. Employees were encouraged to talk about what they liked and do not like, what they found helpful or what did not help.

\subsection{Level 6: The Art of Web2.0 and Leadership 2.0 in action}

With Web2.0, the EHS Director is no longer the only person who can share best practices on Safety issues. He is not the only expert who can publish Safety content on the intranet. All employees can now submit a Safety moment online and share their best practices from their own experience. The EHS Director becomes a coach, a facilitator to help people to make sense of Safety systems and policies. He helps to clarify misunderstandings. In the process, he comes to understand why staff do not practice Safety act as expected. By opening up the dialogue and allowing staff to voice dissent and alternative views, the Safety Program becomes more robust, human and less seen as merely a compliance and bureaucratic exercise. The ultimate goal is the same: to achieve a zero tolerance Safety Culture. It is the pathway to get there that has changed.

This example shows that the art of Web2.0 design is about blending stories, selfreflection, communication, information, knowledge and documents by design. This disciplined approach to design Web2.0 applications, informed by SMM, rests on an alternative set of assumptions about 'knowledge' that zero in on the central SMM 
assumptions about gappiness in terms of how human beings make and unmake sense of their realities. With this approach, knowledge management focuses on the process of knowing, learning, unlearning or simply speaking -- all seen as 'knowledging'. We propose leaders who take on board this alternative set of values and assumptions have the secret ingredients to a new kind of Leadership 2.0 - to reap the benefits of Web2.0.

In his evaluation of these efforts, Mark Clark, ERM's EHS Director said, "Companies can reap the benefits of Web2.0 only if there is a willingness to establish a genuine two-way dialogue with all staff. While Web2.0 allow users to generate content, my team and I need to constantly listen, read suggestions, stories and ideas submitted by staff and provide feedback and guidance to the employees based on their needs.".

\section{Conclusion}

In this paper, Dervin's Sense-Making Methodology is introduced and a practical example is provided to demonstrate a discipline approached to design Web2.0 applications at ERM. The design of knowledge management practices based on an explicit set of metatheoretical assumptions about how communication can work better is critical for developing common understandings, allowing meaningful and constructive debates, and ultimately advancing the knowledge management discipline (Dervin, 2003).

Web2.0 is generally regarded as easy because any users can generate any content at anytime they wish. There is a danger that KM practitioners assume that the application of Web2.0 does not require any design effort, whereas in fact, it requires our closest attention to communication procedures. There is a common saying that "put the wiki or blog in place, let people run with it, and it will catch fire'. The author argues that the design of Web2.0 applications must be rigorous and well thought through. This example we have provided here suggests that a well-developed (which takes a lot of hard work), allows users to feel it is a breeze to use the tool for having meaningful dialogue.

This paper highlights an example of designing a 'Safety Moment' project informed by Sense-Making Methodology. SMM does not provide a recipe to design a one-size-fits-all solution. Rather, it provides a framework of assumptions and a set of values that leaders/designers can draw upon in their designs. In the project that serves as exemplar here, SMM allowed leaders/designers to consider six aspects of 'knowledging' when introducing a blog:

1. A conscious decision to use a blog functionality to promote genuine twoway dialogue instead of a transmission-based top-down communication approach.

2. Using SMM informed questions to discipline the blog posts and the blog comments.

3. Using the blog to facilitate lateral discussion rather than top-down communication. This means that the EHS director had to lower his ego to consciously ask for dissent, tolerate alternative views and learn from staff.

4. Valuing every employee's input by ensuring that the blog design did not silence certain voices. This included allowing anonymous posting to address power issues or to help colleagues who are less technically savvy be comfortable participating. 
5. Using blog writing as a learning tool to promote self-reflective learning. This means expanding the scope of knowledge sharing to sharing with oneself and blending learning with knowledging.

6. Welcoming the surprises that come when you open genuine online dialogue. Some of the surprises are hard to hear; some are immediately useful innovations.

Too often, KM practitioners bemoan -- how can we get employees to be willing to share their knowledge and adopt best practices. How can we use Web2.0 to do this. We propose that these questions miss the point. We propose that knowledging must rest on sound principles of communication. We believe SMM provides an avenue that permits the conscious design of tools that are genuinely communicative and dialogic so they can address the needs of living, breathing human beings. We propose that there needs to be a new kind of Leadership 2.0 that does more than call for dialogue but implements in ways that permit us to see how knowledging is communication-based and how it involves more than sharing but reflecting and muddling and learning as well. We submit that this is the secret ingredient that will allow us to fully reap the benefits from Web2.0 for knowledge management. While the project described here is only a beginning and there is much still to learn about designing KM systems as knowledging systems, we judge this beginning as fruitful.

\section{References}

1. Brown, J. S., \& Duguid, P. (2000). The social life of information. Boston, Massachusetts: Harvard Business School Press.

2. Browning, L., \& Boudes, T. (2005). The use of narrative to understand and respond to complexity: A comparative analysis of the Cynefin and Weickian models. E:CO, 7 (3-4), 32-39.

3. Cheuk, B. (2009). Bringing Health \& Safety to Life. Inside Knowledge Magazine, $10(9)$.

4. Cheuk, B. (2008). Delivering business value through Information Literacy in the workplace. Libri, 57(3).

5. Cheuk, B. (2007). It's more than technology: How ERM has embraced web2.0 to address environmental issues. Paper presented at the Online Information Conference 2007, London.

6. Denning, S. (2000). The Springboard: How Storytelling ignites action in knowledge-era organizations. KMCI Press.

7. Dervin, B. (1989). Audience as listener and learner, teacher and confidante: The Sense-Making approach. In R. E. Rice \& C. K. Atkin (Eds.), Public communication campaigns (2nd ed., pp. 67-86). Newbury Park, CA: Sage. Reprinted in: B. Dervin \& L. Foreman-Wernet (with E. Lauterbach) (Eds.). (2003). Sense-Making Methodology reader: Selected writings of Brenda Dervin (pp. 215232). Cresskill, NJ: Hampton Press.

8. Dervin, B., \& Naumer, C. (2010). Sense-Making. In Bates, M. J. \& Maack, M.N. Encyclopedia of Library and Information Science. Third Edition, 1:1, 4697-4707. Taylor and Francis.

9. Dervin, B., \& Reinhard, C. (2010). Communication and communication studies. In Bates, M. J. \& Maack, M.N. Encyclopedia of Library and Information Science. Third Edition, 1:1, 1169-1181. Taylor and Francis. 
10. Dervin, B. (1992). From the mind's eye of the user: The Sense-Making qualitativequantitative methodology. In J. D. Glazier \& R. R. Powell (Eds.), Qualitative research in information management: 61-84. Englewood, CO: Libraries Unlimited.

11. Dervin, B. (1998). Sense-making theory and practice: an overview of user interests in knowledge seeking and use. Journal of Knowledge Management, 2(2), 36-46.

12. Dervin, B. (1999). Chaos, order and Sense-Making: A proposed theory for information design. In R. Jacobson (Ed.), Information design: 35-57. Cambridge, MA: MIT Press.

13. Dervin, B. (2008). Interviewing as dialectical practice: Sense-Making Methodology as exemplar. Presented at International Association of Media and Communication Research (IAMCR) Meeting, Stockholm, Sweden: 20-25.

14. Dervin, B., \& Foreman-Wernet, L. (2003). Sense-Making Methodology Reader: selected writings of Brenda Dervin. Cresskill, New Jersey: Hampton Press.

15. Dervin, B. (2010). Hidden passions, burning questions. The other side of so-called mass audiences, pp. 243-264. In: Foreman-Wernet, L. and Dervin, B..Audiences and the Arts: Communication Perspectives. Creskill, NJ: Hampton Press.

16. Dervin, B. (2003). Human studies and user studies: a call for methodological interdisciplinarity. Information Research, 9(1). http://InformationR.net/ir/91/paper166.html.

17. Dervin, B. (2003). Verbing communication: Mandate for disciplinary invention. In B. Dervin \& L. Foreman-Wernet (with E. Lauterbach) (Eds.). Sense-Making Methodology reader: Selected writings of Brenda Dervin (pp. 101-110). Cresskill, NJ: Hampton Press.

18. Fairhurst, G. T., \& Putnam, L. L. (2004). Organizations as Discursive Constructions. Communication Theory, 14(1), 5-26.

19. Hildreth, P. M., \& Kimble, C. (2002). The duality of knowledge. Information Research, 8(1). http://informationr.net/ir/8-1/paper142.html.

20. McAfee, A. (2006). Enterprise2.0: The dawn of emergent collaboration. Sloan Management Review, 47(3), reprint no 47306.

21. Nonaka, I., \& Takeuchi, H. (1995). The knowledge-creating company. New York: Oxford University Press.

22. Nonaka, I., \& Peltokorpi, V. (2006). Objective and subjectivity in knowledge management: a review of 20 top articles. Knowledge and Process Management, 13(2), 73-82.

23. Putnam, L. L., \& Krone, K.J. (Eds.). (2006). Organizational Communication (5 volume set). London: Sage.

24. Snowden, D. (2002). Complex acts of knowing: paradox and descriptive selfawareness. Journal of Knowledge Management, 66(2), 100-111.

25. Snowden, D., \& Stanbridge, P. (2004). The landscape of management: creating the context for understanding social complexity. E:CO, Special double issue, 6(1-2), $140-148$

26. Souto, P. C., Dervin, B., \& Savolainen, R. (2008). Designing for knowledge worker informings: An exemplar application of Sense-Making Methodology. Presented at American Society for Information Science and Technology, Columbus, Ohio, October 24-29.

27. Stephens, R. (2009). Blog: http://www.collaborage.com (dated 22 July 2009). 
28. Wilson, T. (2002). The nonsense of 'knowledge management'. Information Research, 8(1). October 2002. http://informationr.net/ir/8-1/paper144.html\#sch67 Retrieved on 8 July 2006.

29. Weick, K. E., \& Browning, L.D. (1986). Argument and narration in organizational communication. Journal of Management, 12(2), 243-259.

30. Weick, K. E., \& Sutcliffe, K. M. (2001). Managing the Unexpected: Assuring High Performance in an Age of Complexity. Jossey-Bass: San Francisco, CA.

31. Wenger, E. (1998). Communities of Practice: learning, meaning and identity. New York: Cambridge University Press. 